\title{
Structural and functional analysis of tomato sterol C22 desaturase
}

\author{
Laura Gutiérrez-García', Montserrat Arró ${ }^{1,2}$, Teresa Altabella ${ }^{1,3}$, Albert Ferrer ${ }^{1,2}$ and Albert Boronat ${ }^{1,4^{*}}$ (D)
}

\begin{abstract}
Background: Sterols are structural and functional components of eukaryotic cell membranes. Plants produce a complex mixture of sterols, among which $\beta$-sitosterol, stigmasterol, campesterol, and cholesterol in some Solanaceae, are the most abundant species. Many reports have shown that the stigmasterol to $\beta$-sitosterol ratio changes during plant development and in response to stresses, suggesting that it may play a role in the regulation of these processes. In tomato (Solanum lycopersicum), changes in the stigmasterol to $\beta$-sitosterol ratio correlate with the induction of the only gene encoding sterol C22-desaturase (C22DES), the enzyme specifically involved in the conversion of $\beta$-sitosterol to stigmasterol. However, despite the biological interest of this enzyme, there is still a lack of knowledge about several relevant aspects related to its structure and function.

Results: In this study we report the subcellular localization of tomato C22DES in the endoplasmic reticulum (ER) based on confocal fluorescence microscopy and cell fractionation analyses. Modeling studies have also revealed that C22DES consists of two well-differentiated domains: a single N-terminal transmembrane-helix domain (TMH) anchored in the ER-membrane and a globular (or catalytic) domain that is oriented towards the cytosol. Although TMH is sufficient for the targeting and retention of the enzyme in the ER, the globular domain may also interact and be retained in the ER in the absence of the N-terminal transmembrane domain. The observation that a truncated version of C22DES lacking the TMH is enzymatically inactive revealed that the N-terminal membrane domain is essential for enzyme activity. The in silico analysis of the TMH region of plant C22DES revealed several structural features that could be involved in substrate recognition and binding.
\end{abstract}

Conclusions: Overall, this study contributes to expand the current knowledge on the structure and function of plant C22DES and to unveil novel aspects related to plant sterol metabolism.

Keywords: Tomato, Sterol metabolism, Stigmasterol, $\beta$-Sitosterol, Cytochrome P450, Sterol C22-desaturase, endoplasmic reticulum

\section{Background}

Sterols are isoprenoid-derived lipids that play an essential role in the regulation of membrane fluidity, permeability and function [1, 2]. Sterols share a common structure based on the cyclopentane perhydro phenanthrene ring

\footnotetext{
* Correspondence: aboronat@ub.edu

${ }^{1}$ Center for Research in Agricultural Genomics (CSIC-IRTA-UAB-UB), Bellaterra, Barcelona, Spain

${ }^{4}$ Department of Biochemistry and Molecular Biomedicine, Faculty of Biology, University of Barcelona, 08028 Barcelona, Spain

Full list of author information is available at the end of the article
}

system with a hydroxyl group at position C3, methyl groups at positions $\mathrm{C} 10$ and $\mathrm{C} 13$ and a side chain of variable length attached to C17 [3]. Contrary to other eukaryotic organisms, plants are characterized by producing a high diversity of sterols that mostly differ in the nature of the side chain attached to $C 17$, being $\beta$ sitosterol, stigmasterol and campesterol the most abundant ones, and in some Solanaceae also cholesterol. In plants, sterols are present in free form and also in conjugated forms as steryl esters, steryl glycosides and acyl steryl glycosides. While free sterols and steryl glycosides

(c) The Author(s). 2021 Open Access This article is licensed under a Creative Commons Attribution 4.0 International License, which permits use, sharing, adaptation, distribution and reproduction in any medium or format, as long as you give appropriate credit to the original author(s) and the source, provide a link to the Creative Commons licence, and indicate if changes were made. The images or other third party material in this article are included in the article's Creative Commons licence, unless indicated otherwise in a credit line to the material. If material is not included in the article's Creative Commons licence and your intended use is not permitted by statutory regulation or exceeds the permitted use, you will need to obtain permission directly from the copyright holder. To view a copy of this licence, visit http://creativecommons.org/licenses/by/4.0/. The Creative Commons Public Domain Dedication waiver (http://creativecommons.org/publicdomain/zero/1.0/) applies to the data made available in this article, unless otherwise stated in a credit line to the data. 
are mainly found in the plasma membrane (PM), steryl esters accumulate in cytoplasmic lipid droplets [4].

Sterols are known to be crucial for the function of the PM as they modulate its physicochemical properties, as well as the formation of microdomains (also known as lipid rafts) that are involved in many relevant cellular processes such as cell to cell interactions, signal transduction, membrane transport, protein trafficking and stress responses $[5,6]$. In plants, the right function of the PM depends on the balanced levels of campesterol, $\beta$-sitosterol and stigmasterol [7]. In particular, changes in the $\beta$-sitosterol/stigmasterol ratio have been proposed to influence different developmental processes and stress responses [7]. $\beta$-Sitosterol and stigmasterol only differ in the double bond present at position C22 in stigmasterol side chain (Additional file 1: Fig. S1). However, despite their high structural similarity these sterols have a differential effect on the physicochemical properties of the PM [8]. Stigmasterol-enriched membranes are less permeable and, therefore, show a decreased leakage $[9,10]$. Therefore, the level of $\beta$-stigmasterol in the PM is expected to be tightly regulated during plant development and stress responses [11-13].

Stigmasterol is the end product of the 24-ethyl branch of the sterol biosynthetic pathway and is synthesized from $\beta$-sitosterol by the action of the enzyme sterol C22desaturase (C22DES) (Additional file 1:Fig. S1) [11, 14]. C22DES, also known as CYP710, belongs to the cytochrome P450 (CYP) protein family, which includes enzymes involved in numerous biosynthetic and xenobiotic pathways in all living organisms. CYP proteins share a common catalytic center including a heme-iron binding domain. NADPH acts as the electron donor in the reaction catalyzed by C22DES through the action of cytochrome $\mathrm{P} 450$ reductase, a membrane-bound protein localized in the ER membrane [14-16]. C22DES is phylogenetically related to CYP51, a CYP protein having sterol 14-demethylase activity. CYP51 is common to the plant, yeast and animal sterol biosynthetic pathways [17, 18], and there is evolutionary evidence suggesting that these enzymes already existed in the most ancient eukaryotes [19]. Since C22DES acts downstream of CYP51 in the sterol biosynthesis pathway it has been proposed that it evolved from a CYP51 gene duplication [19, 20].

Plant C22DES was cloned and characterized at the biochemical level more than one decade ago [14, 21, 22]. However, there are several functional and structural aspects related to this enzyme that still remain unknown. One of them concerns the elucidation of its subcellular localization, an aspect that is particularly remarkable considering that C22DES may act on $\beta$ sitosterol synthesized in the ER during de novo sterol biosynthesis and/or also on $\beta$-sitosterol present in the PM (either in free or conjugated form). Although it is widely accepted that free sterol biosynthesis occurs in the ER [23-25], the participation of the PM in the final steps of the sterol pathway has not been excluded [3]. All plant CYP proteins described so far are membrane-bound and mainly localized in the ER. However, some particular CYP proteins have been reported in other subcellular localizations such as mitochondria, plastids and the PM [26, 27]. Therefore, the elucidation of the subcellular localization of C22DES represents a relevant issue in plant sterol metabolism. Other important aspects related to the characterization of C22DES are the identification of structural and functional motifs involved in the intracellular targeting of the enzyme as well as in its membrane topology and catalytic function. Some of these issues have been addressed in the present work using tomato C22DES, which was chosen for this study not only because this plant is one of the most important crops worldwide but also because, in contrast to other plant species, tomato contains a single gene coding for this enzyme $[11,17]$.

\section{Results}

\section{Tomato C22DES localizes in the ER}

To define the subcellular location of C22DES, a chimeric protein containing the entire tomato C22DES coding sequence fused at the $\mathrm{N}$-terminal end of the green fluorescent protein (GFP) (C22DES-GFP) was transiently expressed in Nicotiana benthamiana leaves. As revealed by confocal fluorescence microscopy, C22DES-GFP exhibited a typical ER-like pattern. This fluorescence pattern was essentially the same observed in cells coexpressing T3RE protein fused to the red fluorescent protein (RFP) (T3RE-RFP), which was used as a specific marker for ER-localization [28] (Fig. 1). Actually, merging the fluorescence of both channels revealed a clear overlap of the two images.

To make sure that the C-terminal GFP tag was not affecting neither the correct targeting of C22DES nor its catalytic activity, the stigmasterol levels of the agroinfiltrated $N$. benthamiana leaves expressing either the native C22DES or the chimeric C22DES-GFP variant were determined and compared to those of leaves agroinfiltrated with the empty expression vector that were used as a control. As shown in Fig. 2, the total stigmasterol level increased by about $75 \%$ in a similar way in both cases. These results revealed that the chimeric enzyme was properly targeted to the subcellular compartment(s) were its substrate ( $\beta$-sitosterol) is found and also provided an in vivo assay to evaluate the enzyme activity of a set of C22DES-GFP derivatives described below. 


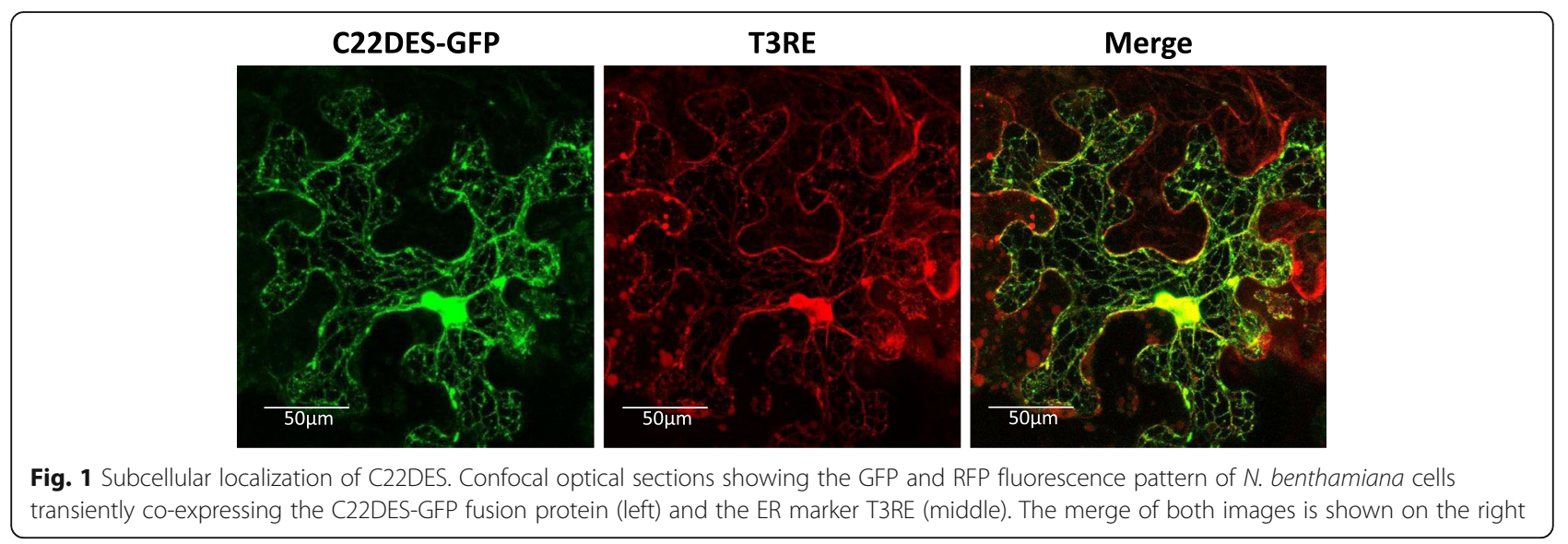

\section{D-modeling of tomato C22DES}

The tertiary structure of tomato C22DES was modeled with $100 \%$ confidence using the single highest scoring template of the Saccharomyces cerevisiae lanosterol 14 $\alpha$ demethylase (CYP51) crystal structure [29], which has previously been reported to be an ER-membraneassociated enzyme [30]. The overall tertiary structure predicted for C22DES was very similar to that of yeast CYP51 although a remarkable difference was observed in the N-terminal region. While in CYP51 it is composed by an N-terminal amphipathic $\alpha$-helix followed by a transmembrane $\alpha$-helix [29], in C22DES this region is shorter and contains a single putative transmembrane $\alpha$-helix (residues 1-28), that was referred to as TMH (Fig. 3a). Moreover, an interaction model of C22DES with cell membranes, generated using the PPM web server of the Orientations of Proteins in Membranes (OPM) database [31], predicted two other membrane contact regions in the protein sequence, namely MCR1 (residues 38-58) and MCR2 (residues

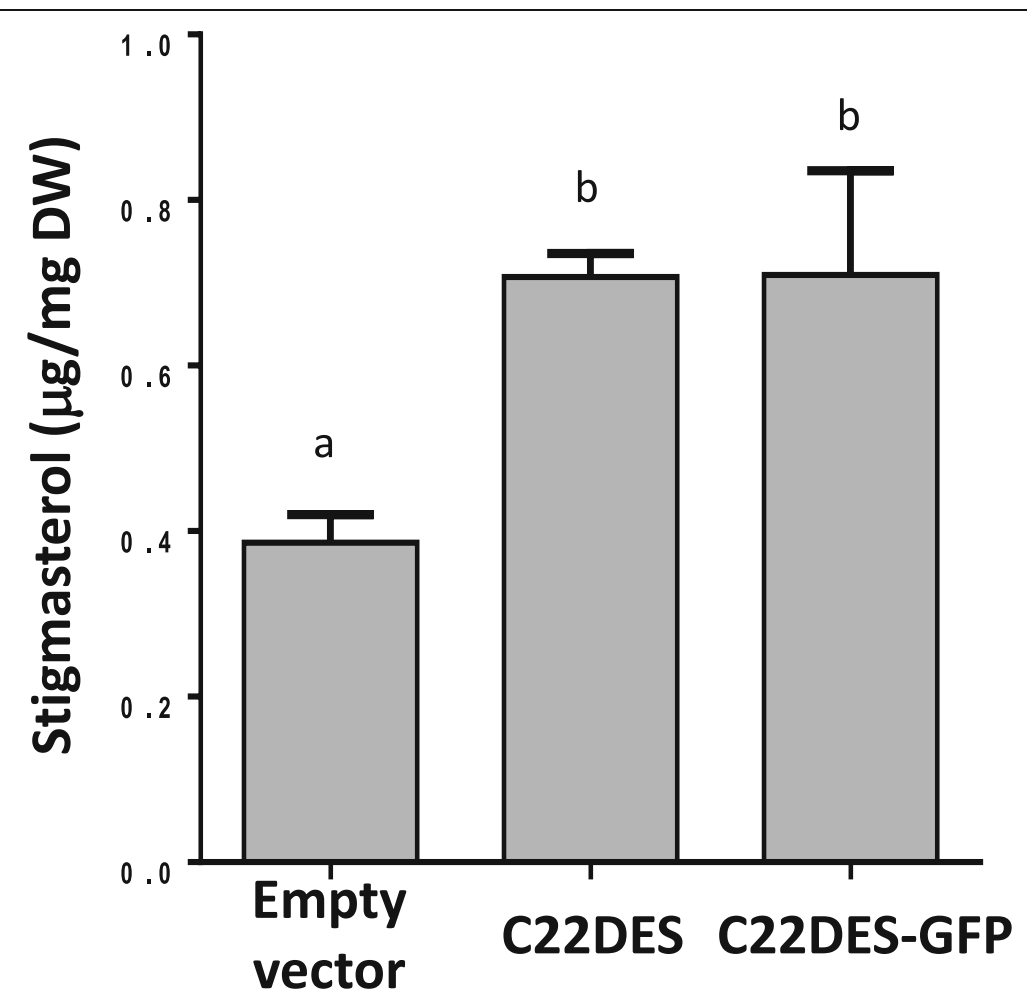

Fig. 2 In vivo enzymatic activity of C22DES and C22DES-GFP. Stigmasterol levels in total sterol fractions of $N$. benthamiana leaves transiently expressing C22DES and C22DES-GFP. Values are mean values \pm SD of three technical replicates $(n=3)$. Lowercase letters indicate significant differences among mean values relative to those in leaf samples expressing the empty vector (one-way ANOVA with Dunnett's multiple comparisons test). DW: Dry weight 

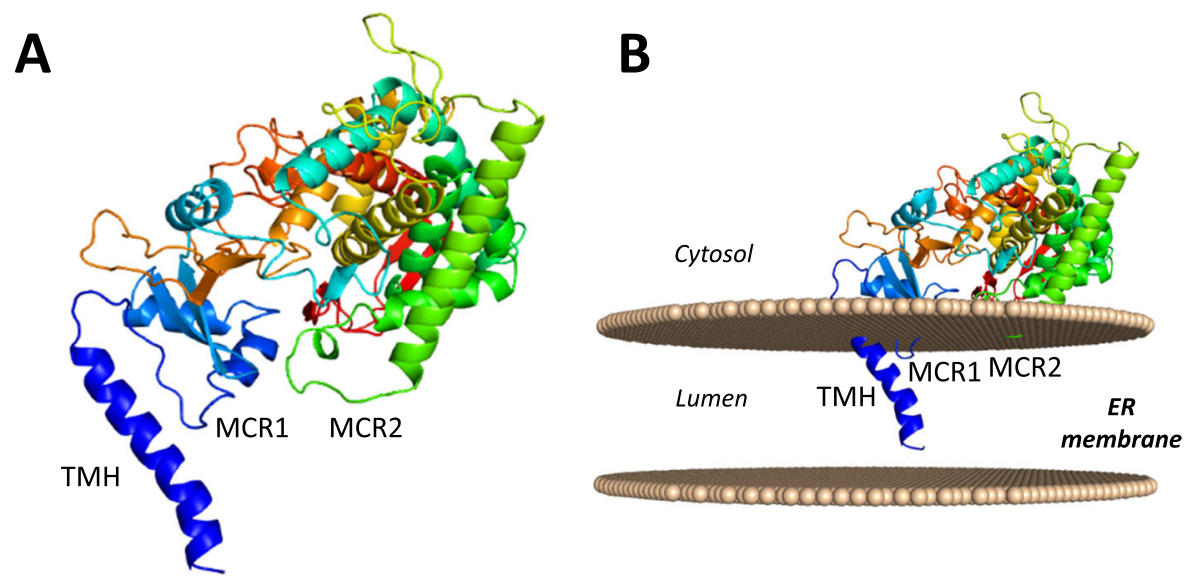

C

MCR1

D

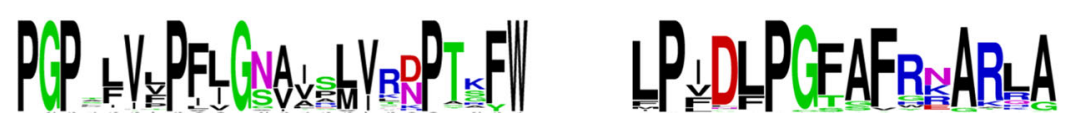

Fig. 3 Predicted tomato C22DES tertiary structure. a Overall predicted fold of tomato C22DES. b Predicted orientation of C22DES in a dioleoylphosphatidylcholine (DOPC) membrane. The predicted N-terminal transmembrane helix (TMH) and the membrane contact regions MCR1 and MCR2 are indicated. $\mathbf{c}$ and $\mathbf{d}$ Sequence logo of the consensus MCR1 and MCR2 sequences obtained from the alignment of the plant C22DES proteins indicated in Additional file 2: Table S1

227-233) (Fig. 3a and b). MCR1 is a proline-rich motif located in close proximity to $\mathrm{TMH}$ and highly conserved among C22DES from different plant species (Fig. 3c) whereas MCR2 is less conserved (Fig. 3d) and localizes in the globular domain next to a long amphipathic $\alpha$ helix predicted in all plant C22DES (Fig. 3a and b). These results are consistent with our previous finding showing that functional tomato C22DES localizes into the ER membrane of $N$. benthamiana cells.

\section{TMH is sufficient to target and retain tomato C22DES in the ER membrane}

To study the role of the ER interacting sequences predicted in the $\mathrm{N}$-terminal region of tomato C22DES (TMH and MCR1), the amino acid sequences containing residues 1 to 75 (including both TMH and MCR1), residues 1 to 37 (including only TMH), and residues 28 to 66 (including only MCR1) were fused at the $\mathrm{N}$-terminal end of GFP (Fig. 4a). The MCR1 motif was included in these studies because of its close proximity to TMH and its predicted interaction with the ER membrane (Fig. 4b). The subcellular localization of the resulting chimeric proteins (TMH + MCR1-GFP, TMH-GFP, and MCR1-GFP, respectively) was analyzed by confocal microscopy after transient expression in $N$. benthamiana leaves. The fluorescence distribution of TMH + MCR1GFP and TMH-GFP resulted in a typical ER localization pattern (Fig. 4b). In contrast, MCR1-GFP showed a fluorescence compatible with a cytosolic localization with fluorescence also present the nucleus (Fig. 4b). However, MCR1-GFP also showed some overlap with that of T3RE (Fig. 5c). These results are in agreement with the fact that MCR1 may confer the ability of MCR1-GFP to interact with the ER, reinforcing in this way the functional role of this motif in the interaction of C22DES with the ER. The localization of green fluorescence in the nucleus may be explained considering that at least part of the expressed MCR1-GFP was present in soluble form in the cytosol.

The globular domain of tomato C22DES interacts with the ER in the absence of TMH

It has been reported that the globular domain of several CYP proteins interacts with the ER membrane in the absence of the transmembrane domain [32-35]. To determine if this is the case in tomato C22DES, a N-terminal truncated form of the enzyme lacking the TMH region (residues 2 to 27) was fused to the N-terminal end of RFP and the resulting protein (C22DES $\triangle 2-27-R F P$ ) transiently expressed along with TMH-GFP in $N$. benthamiana leaves. The fluorescence distribution of C22DES $\triangle 2-27-R F P$ showed a typical reticular pattern and co-localization with TMH-GFP (Fig. 5a). These results indicated that the globular domain of tomato C22DES was interacting and retained in the ER in the absence of TMH. Fluorescence Recovery After 


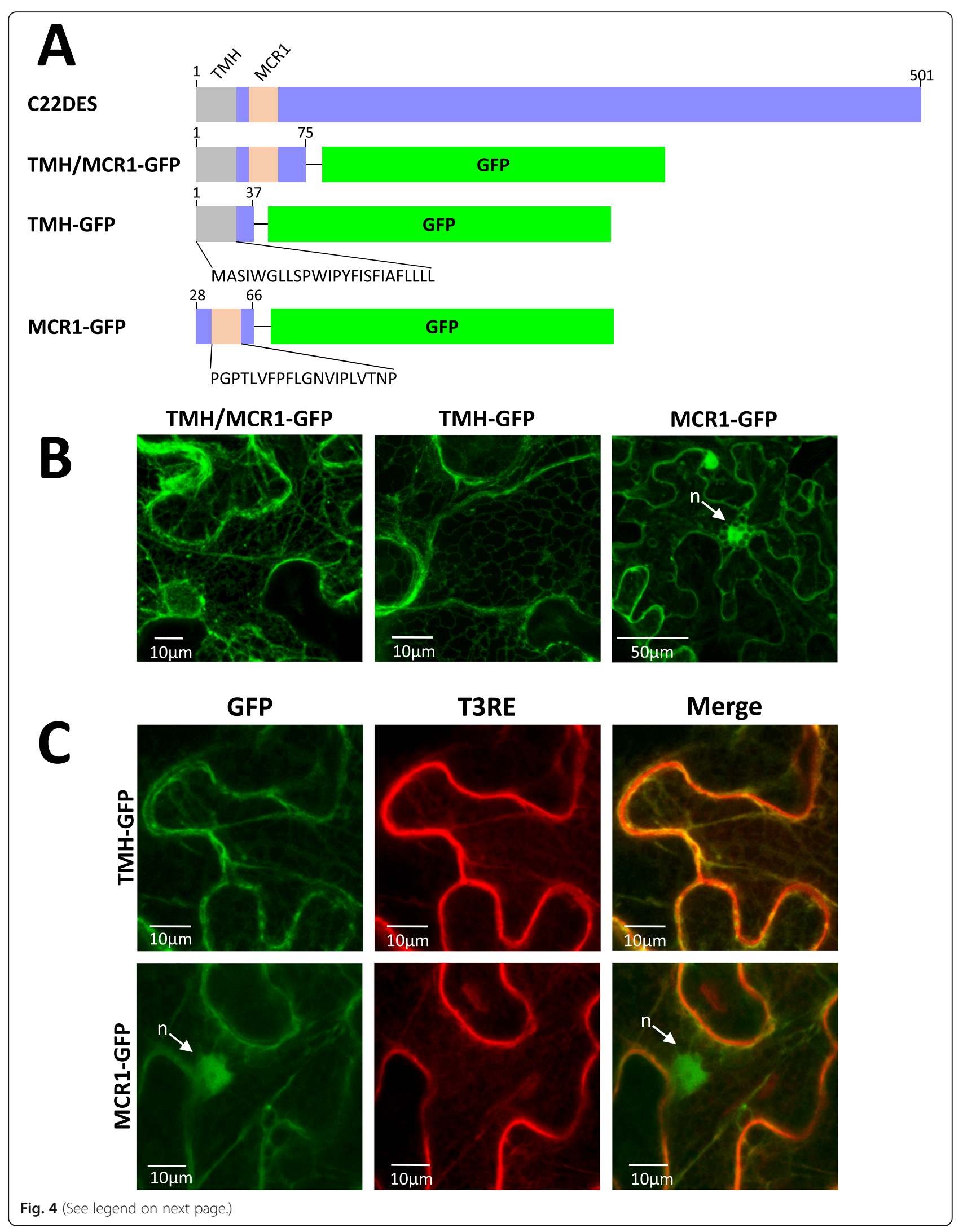


(See figure on previous page.)

Fig. 4 Role of $\mathrm{TMH} 1$ in the targeting and retention of C22DES in the ER membrane. a Schematic representation of the GFP fusion constructs generated to study the role of TMH and MCR1 in the targeting and retention of C22DES in the ER. Grey boxes indicate the transmembrane helix $(\mathrm{TMH})$, orange boxes correspond to the MCR1 motif and green boxes correspond to the GFP protein. The amino acid sequence of TMH and MCR1 are shown below the corresponding regions. $\mathbf{b}$ Confocal optical sections showing the GFP fluorescence pattern of $N$. benthamiana cells transiently expressing TMH + MCR1-GFP, TMH-GFP, and MCR1-GFP. The arrow indicates the cell nucleus (n). c Close-up view of the fluorescence pattern of TMH-GFP and MCR1-GFP (left), T3RE (middle) and the corresponding merged images (right)

Photobleaching (FRAP) analysis [36, 37] was performed to reinforce these results using the brassinosteroid receptor BRL3 fused to GFP (BRL3-GFP) [38] and GFP as membrane-bound and cytosolic control proteins, respectively. As shown in Fig. 5b, C22DES $\triangle 2-27-R F P$ showed a recovery rate similar to that of BRL3-GFP, thus confirming its behavior as an integral membrane protein. In agreement with this result, immunoblot analysis using anti-GFP antibodies of the cytosolic and membrane fractions obtained from $N$. benthamiana leaves transiently expressing TMH-GFP, C22DES-GFP and C22DES $\triangle 2-27-$ GFP demonstrated that they were present in the membrane fraction (Fig. $5 \mathrm{c}$ and d). In the immunoblot analysis C22DES $\triangle 2-27-G F P$ was used instead of C22DES $\triangle 2-27-R F P$ because anti-GFP antibodies do not recognize the RFP.

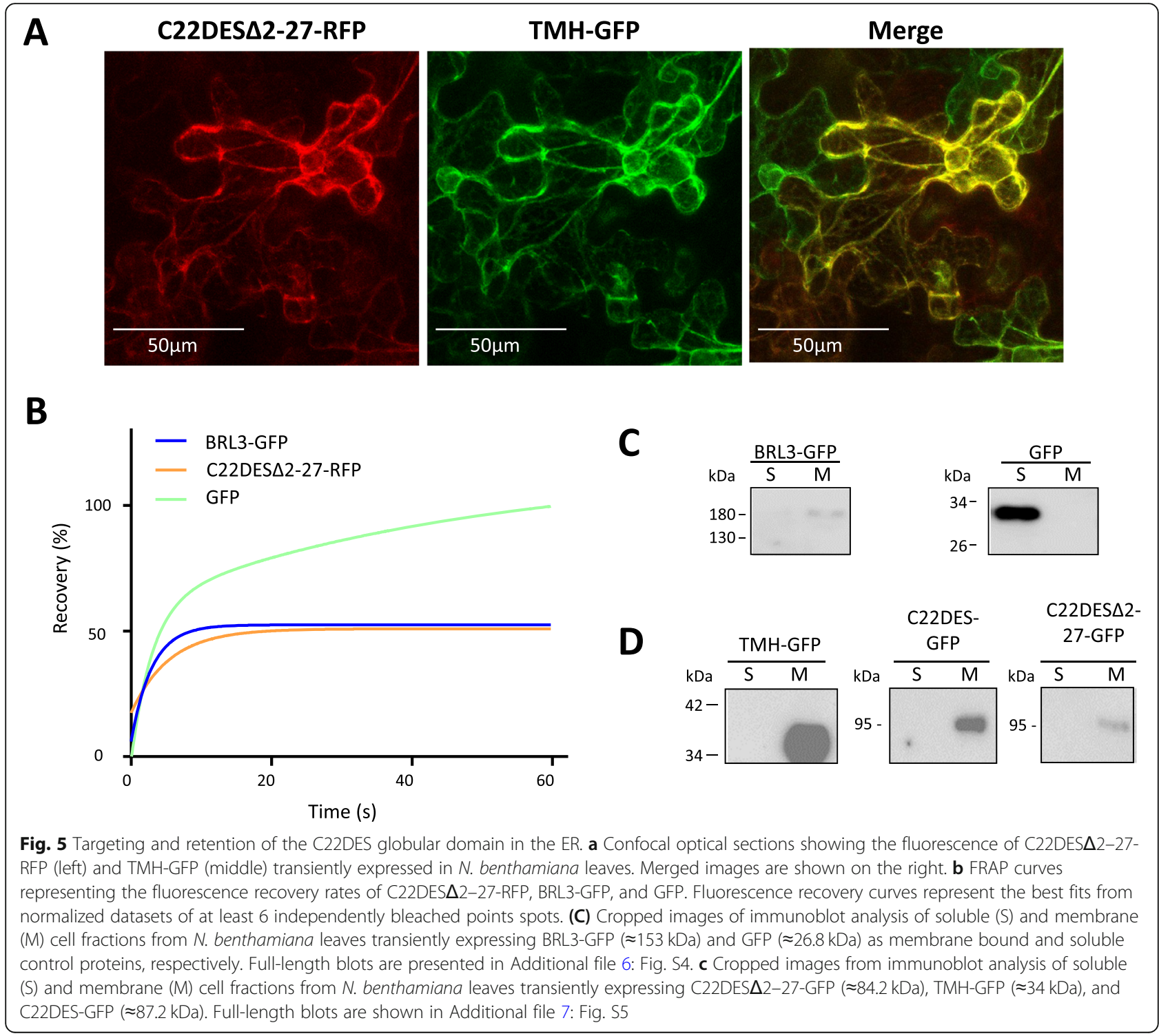


TMH is required for tomato C22DES activity

The results reported above suggested that TMH could have other functions in addition to anchor the enzyme to the ER. To explore this possibility, C22DES $\Delta 2-27$ GFP was transiently expressed in $N$. benthamiana leaves to evaluate its enzyme activity. C22DES-GFP was expressed in parallel as a positive control. The expression of both proteins was determined by immunoblot analysis using anti-GFP antibodies (Fig. 6a). As expected, the samples expressing C22DES-GFP showed an increase in the total stigmasterol content (Fig. 6b). However, in the case of C22DES $\triangle 2-27-G F P$, the stigmasterol content was similar to that found in the leaves agroinfiltrated with the empty expression vector (Fig. 6b), thus indicating that $\mathrm{TMH}$ is necessary for enzyme activity.

\section{The N-terminal region of C22DES from different plant species share features that may be relevant for enzyme activity}

The sequence alignment of C22DES from different plant species showed that both the length and the sequence of the TMH was poorly conserved (Fig. 7). However, a careful inspection of these sequences revealed the presence of several common features shared by all plant C22DES proteins. One of them was the high number of threonine and serine residues in the $\mathrm{N}$-terminal half of

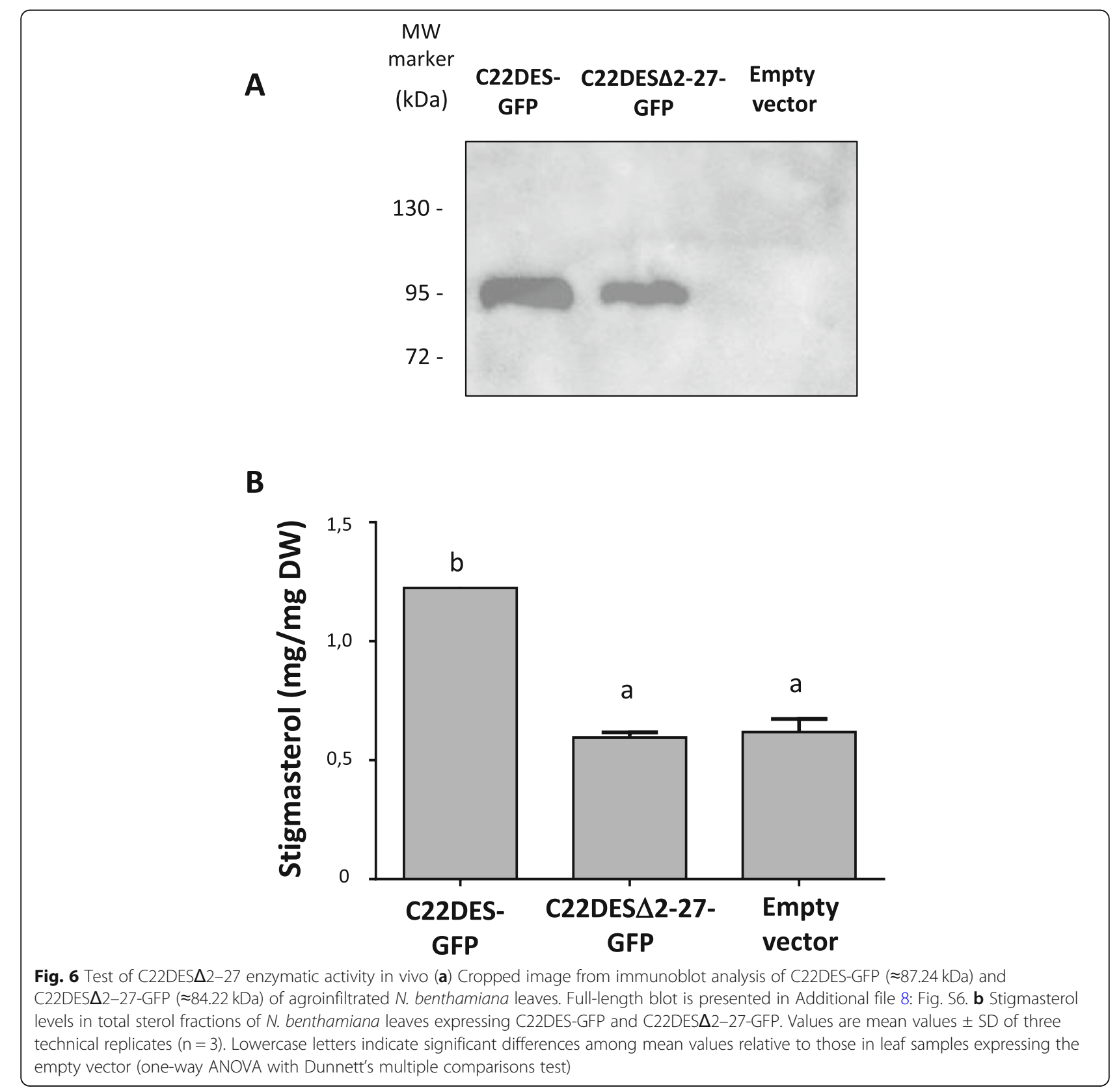




\begin{tabular}{|c|c|c|c|}
\hline \multicolumn{2}{|r|}{$\mathrm{TMH}$} & MCR1 & \\
\hline & \multirow{2}{*}{\multicolumn{2}{|c|}{ 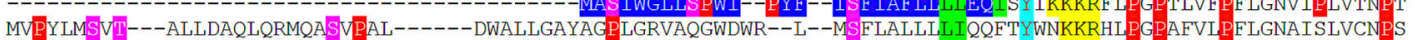 }} & \\
\hline & & & \\
\hline & \multirow{2}{*}{\multicolumn{2}{|c|}{ 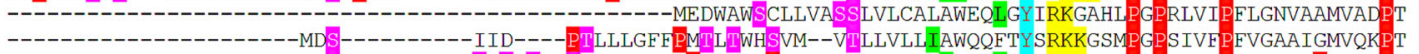 }} & \\
\hline & & & \\
\hline & \multirow{2}{*}{\multicolumn{2}{|c|}{ 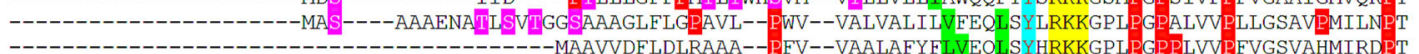 }} & \\
\hline & & & \\
\hline & \multicolumn{2}{|c|}{ 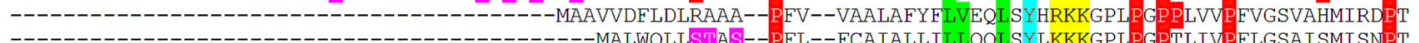 } & \\
\hline & \multicolumn{2}{|c|}{--- } & \\
\hline & \multirow{2}{*}{\multicolumn{2}{|c|}{$\begin{array}{l}---1 \\
-1\end{array}$}} & \\
\hline & & & \\
\hline & \multicolumn{2}{|c|}{ 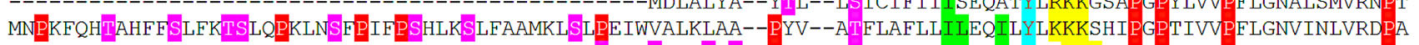 } & \\
\hline & \multirow{2}{*}{\multicolumn{2}{|c|}{$\begin{array}{l}\text { - } \\
-\end{array}$}} & \\
\hline & & & \\
\hline & \multicolumn{2}{|c|}{----- } & \\
\hline & \multirow{2}{*}{\multicolumn{2}{|c|}{ 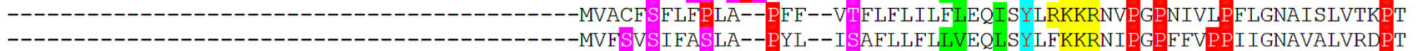 }} & \\
\hline & & & \\
\hline & \multicolumn{2}{|c|}{ 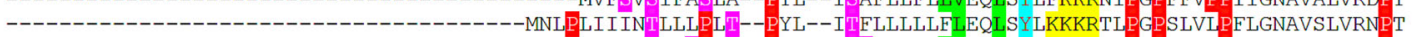 } & \\
\hline & \multicolumn{2}{|c|}{ 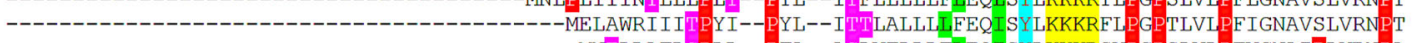 } & \\
\hline & \multirow{2}{*}{\multicolumn{2}{|c|}{ 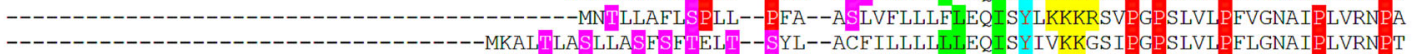 }} & \\
\hline & & & \\
\hline & \multicolumn{2}{|c|}{ 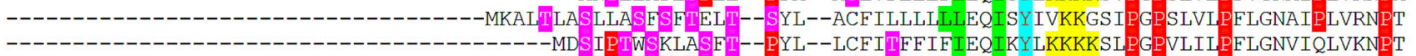 } & \\
\hline & \multicolumn{2}{|c|}{ 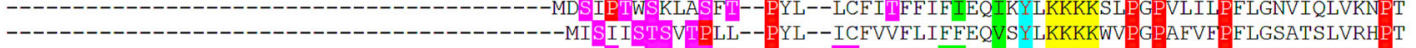 } & \\
\hline & \multirow{2}{*}{\multicolumn{2}{|c|}{ 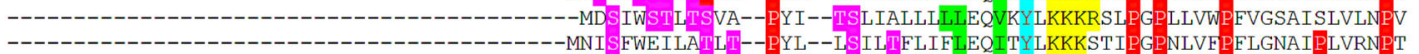 }} & \\
\hline & & & \\
\hline & \multicolumn{2}{|c|}{ 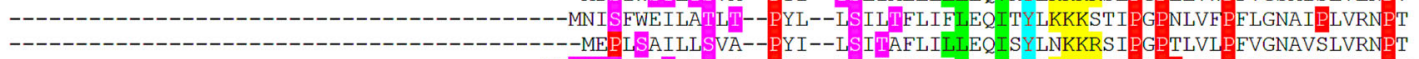 } & \\
\hline & \multicolumn{2}{|c|}{ 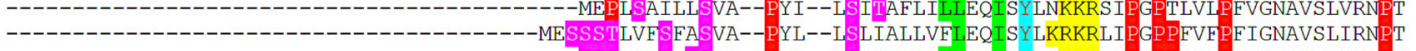 } & 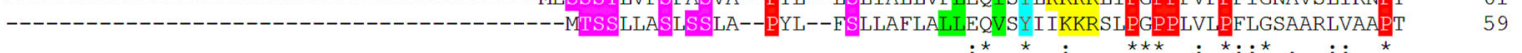 \\
\hline Eugr & \multicolumn{3}{|c|}{$\frac{: * \star::}{\operatorname{CRAC} 1}$} \\
\hline \multicolumn{4}{|c|}{$\begin{array}{l}\text { Fig. } 7 \text { Multiple sequence alignment of the N-terminal region of plant C22DES. The sequence alignment of the N-terminal region of C22DES from } \\
\text { the } 27 \text { plant species listed in Additional file 2: Table S1 is shown. Amino acid residues are numbered on the right. Asterisks denote residues } \\
\text { conserved in all sequences. Colons indicate conservation between amino acid groups of strongly similar properties whereas periods indicate } \\
\text { conservation between amino acid groups of weakly similar properties. Hyphens indicate gaps introduced to optimize the alignment. The tomato } \\
\text { TMH sequence is highlighted in blue; prolines (P) are shown in red, and serine (S) and threonine (T) residues are shown in magenta. The CRAC1 } \\
\text { motif (including the conserved Q27 and Y30 residues) and the MCR1 sequence are also shown. The branched-chain amino-acids [leucine (L), } \\
\text { valine (V) and isoleucine (I)] in CRAC1 are shown in green, tyrosine (Y) in cyan and the dibasic residues [arginine (R) and lysine (K)] in yellow. Soly, } \\
\text { Solanum lycopersicum; KIni, Klebsormidium nitens; Semo, Selaginella moellendorffii; Pisy, Pinus sylvestris; Sppo, Spirodela polyrhiza; Orsa, Oryza sativa; } \\
\text { Deca, Dendrobium catenatum; Phda, Phoenix dactylifera; Anco, Ananas comosus; Amtr, Amborella trichopoda; Bevu, Beta vulgaris; Kafe, Kalanchoe } \\
\text { fedtschenkoi; Potr, Populus trichocarpa; Cicl, Citrus clementina; Gora, Gossypium raimondii; Arth, Arabidopsis thaliana; Frve, Fragaria vesca; Ergu, } \\
\text { Erythranthe guttata; Cusa, Cucumis sativus; Glma, Glycine max; Paso, Papaver somniferum; Jure, Juglans regia; Nenu, Nelumbo nucifera; Daca, Daucus } \\
\text { carota; Cyca, Cynara cardunculus; Vivi, Vitis vinifera; Eugr, Eucalyptus grandis }\end{array}$} \\
\hline
\end{tabular}

THM (Fig. 7). This may be relevant since some studies have described the role of hydroxylated residues in protein transmembrane domains to provide substrate specificity or correct associations with other membrane components through interactions with the hydroxyl group of their polar side chains [39, 40]. Another common feature was the presence of one or more proline residues in the N-terminal half of TMH (Fig. 7). Since proline residues induce a turn of about 30 degrees in $\alpha$-helices, the TMH sequence of most plant C22DES may have one or more turns in their $\mathrm{N}$-terminal half.

The alignment shown in Fig. 7 also showed the conservation of a glutamine and a tyrosine residue (corresponding to Q27 and Y30 in the tomato sequence) and the presence of a short stretch of positively charged residues between TMH and MCR1. Interestingly, the conserved tyrosine residue and the positively charged residues were identified as elements of a cholesterol recognition/interaction amino acid (CRAC) motif defined by the consensus $-\mathrm{L} / \mathrm{V}-\mathrm{X} 1-5-\mathrm{Y}-\mathrm{X} 1-5-\mathrm{R} / \mathrm{K}$ [41] (Fig. 7). CRAC motifs are usually found in transmembrane helices of membrane proteins. This putative CRAC motif identified in the $\mathrm{N}$-terminal region of C22DES (hereafter referred to as CRAC1) also includes the conserved glutamine residue indicated above.

\section{The globular domain of plant C22DES contains cholesterol recognition/interaction amino acid consensus motifs}

The multiple alignment of plant C22DES (Additional file 2: Table S1) revealed the presence of other conserved cholesterol recognition/interaction amino acid consensus motifs in the globular domain. In addition to the already described CRAC motifs, the globular domain also contains the so called CARC motifs, which correspond to a specular sequence of the CRAC motifs and are defined by the consensus K/R-X1-5-Y/F-X1-5-L/V). CARC motifs may also bind cholesterol although in opposite orientation [42]. Two CRAC motifs (CRAC2 and CRAC4), three CARC motifs (CARC1, CARC2 and CARC3) and one in which a CRAC motif and a CARC motif overlap (CRAC3/ CARC4) were found to be conserved in the globular domain of plant C22DES (Additional file 3: Fig. S2). The identification of such a large number of putative cholesterol-interaction motifs was surprising and led to hypothesize that, at least in some cases, it could merely 
reflect the laxity of these consensus motifs. Since the functional CRAC and CARC motifs reported in the globular domain of membrane proteins are found in $\alpha$-helices $[43,44]$ it is likely that only those motifs located in predicted $\alpha$-helices (CARC2, CARC3, CRAC2 and CRAC3/CARC4) (Additional file 4: Fig. S3) might have a functional role in C22DES. Among them, CARC2, CARC3, and CRAC3/CARC4 could be of special interest as they are present in amphipathic $\alpha$-helices and located near the catalytic site in the upper part of the globular domain (Additional file 4: Fig. S3).

\section{Discussion}

The results obtained in this work demonstrate that tomato C22DES is an ER-resident protein. The 3D modeling of tomato C22DES using the crystal structure of the phylogenetically related lanosterol $14 \alpha$-demethylase (CYP51), an enzyme also involved in sterol metabolism thought to be one of the most ancient and conserved P450s across the kingdoms, predicted the presence of an $\mathrm{N}$-terminal hydrophobic transmembrane domain and two short sequences (MCR1 and MCR2) located in the globular domain which also interact with the ER membrane (Fig. 3). Subcellular localization studies using C22DES derivatives fused to GFP indicated that TMH is sufficient for the targeting and retention of C22DES in the ER (Fig. 4 and 5d). These studies also revealed that the globular domain can interact and be retained in the ER membrane in the absence of TMH (Fig. 5). The sequence conservation of MCR1 and MCR2 among plant C22DES (Figs. 3c and d) supports a role for these sequences in the interaction with the ER membrane.

The mechanisms underlying the interaction and retention of the globular domain of C22DES in the ER remain to be characterized. However, it is likely that they could involve the hydrophobic interaction of MCR1 and MCR2 with the ER membrane and/or its interaction with other ER resident proteins such as NADPH-cytochrome P450 reductase, which is required for the function of CYPs [27, 45]. The interaction between some CYP proteins to form heterodimers, as well as between CYPs and other proteins such as cytochrome b5 and UDP-glucuronosyltransferase (UGT)1A has also been reported [46-50].

The observation that the globular domain of tomato C22DES was enzymatically inactive despite behaving as an integral membrane protein (Fig. 6) revealed that $\mathrm{TMH}$ was also required for enzyme activity. This result was somehow unexpected considering the recent work of Gnanasekaran et al. (2015) showing that the Nterminal region of CYP720B4, a plant cytochrome P450 involved in isopimeric acid biosynthesis, was not essential for the activity of this enzyme when expressed in $N$. benthamiana leaves. However, the functional role of the
$\mathrm{N}$-terminal transmembrane domain of CYPs remains a controversial issue. Thus, while some recombinant CYPs lacking the N-terminal anchor region have been reported to be active in vitro, no activity could be detected in in vivo assays $[34,51,52]$. The differential behavior of the $\mathrm{N}$-terminal region of CYPs may be related, at least in part, with the nature and subcellular availability of their substrates. This would explain why some CYPs show activity under in vitro test conditions in which the substrate is fully available, but not under in vivo assay conditions where the availability of substrate may be a limiting factor. Furthermore, it has been proposed that the $\mathrm{N}$-terminal membrane domain of some CYPs participates in the correct positioning of the globular domain with respect to the membrane during catalysis. Thus, it has been reported that the transient tilting of the globular domain is an essential requirement to allow the interaction of CYPs with their substrates when located within the hydrophobic core of the ER membrane $[53,54]$. In the particular case of C22DES, it can be speculated that it could not interact with its substrate ( $\beta$-sitosterol) unless TMH provides the right anchoring of the globular domain to allow its tilting within the ER membrane during catalysis.

Despite the essential role of TMH in tomato C22DES activity, it was surprising to find that both the length and the amino acid sequence of the $\mathrm{N}$-terminal region of plant C22DES was poorly conserved (Fig. 7). However, a detailed inspection of these sequences revealed two conserved features that could be relevant for enzyme activity: i) the presence of a cholesterol recognition/interaction amino-acid consensus (CRAC) motif, and ii) an enrichment of serine and threonine residues in the N-terminal half of TMH. Cholesterol-binding domains have been the focus of many studies involving computational methods to explore the transmembrane regions of animal proteins for which there is good evidence of their interaction with cholesterol $[41,42]$. The first motif to be identified was termed cholesterol recognition/interaction amino-acid consensus (CRAC) and fulfills the consensus ( $\mathrm{L} / \mathrm{V})-\mathrm{X}_{1-5^{-}}(\mathrm{Y})-\mathrm{X}_{1-5^{-}}(\mathrm{R} / \mathrm{K})$, (where $\mathrm{X}$ is any amino acid) [41, 42, 55]. Another cholesterolbinding motif named CARC corresponds to the mirror version of the CRAC motif with the consensus sequence $(\mathrm{K} / \mathrm{R})-\mathrm{X}_{1-5^{-}}(\mathrm{Y} / \mathrm{F})-\mathrm{X}_{1-5^{-}}(\mathrm{L} / \mathrm{V})[42,55]$. Despite the CRAC motif was initially identified and characterized in animal proteins [55-58], its cholesterol-binding function has also been demonstrated in plants [59]. Interestingly, a CRAC motif able to interact with $\beta$-sitosterol has recently been described in the type 1 cholecystokinin receptor [60]. Thus, it is likely the CRAC1 motif present in the $\mathrm{N}$-terminal region of plant C22DES (CRAC1) may contribute to the interaction of the enzyme with the $\beta$ sitosterol present in the ER membrane. Another feature 
reported in cholesterol-binding regions is the presence of serine and threonine residues. Furthermore, the structural analysis of several cholesterol-binding proteins has led to propose that the hydrophilic side-chain of these amino acids may interact with the C3-hydroxyl group of the cholesterol molecule [61]. Thus, it is likely that the serine and threonine residues present in the $\mathrm{N}$-terminal half of TMH could enhance the interaction of C22DES with $\beta$-sitosterol in the ER, facilitating in this way its interaction with the CRAC1 motif.

The localization of C22DES in the ER was not unexpected considering that other enzymes involved in sterol biosynthesis, such as SMT1, CPI1, HYD1, and DWF/ DIM [5, 62-64] as well as cytochrome P450 reductase, the physiological redox partner of cytochrome P450s, also localize in this cellular compartment [65]. However, the localization of C22DES in the ER raises the question about how this enzyme can act on the major cellular pool of $\beta$-sitosterol present in the PM. It is likely that this process may involve the capacity of the ER to physically interact with the PM at structures known as ERPM contact sites in which both membranes are in close contact [66-68]. The possibility that enzymes located in one membrane may act on substrates present in a different cell membrane, the so-called in trans activity, is not unprecedented [69-72]. Interestingly, specific ER-PM contact sites involved in the regulation of lipidhomeostasis, including phospholipids and sterols, have recently been reported [73]. Furthermore, enzymes involved in lipid biosynthesis have been localized at ERPM contact sites and shown to contribute to their formation [72, 74]. However, and to the best of our knowledge, the involvement of ER-PM contact sites in sterol or lipid homeostasis has not yet been reported in plants, although it has been suggested that the PM-localized tomato Acyl-CoA:sterol acyltransferase (SlASAT1) may act in trans on its substrate cycloartenol in the ER lipid bilayer at ER-PM contact sites to produce cycloartenyl esters [75]. The existence of several conserved CRAC/ CARC motifs in the globular domain of plant C22DES suggests that they could have a role in the interaction of the enzyme with the $\beta$-sitosterol present in the PM. In this respect, the localization of CARC2, CARC3 and CRAC3/CARC4 in amphypathic $\alpha$-helices may be relevant considering that this type of structures has been described to serve not only as membrane interaction domains but also as lipid binding sites [76]. The study of the contribution of these CARC and CRAC motifs in the activity of C22DES on the $\beta$-sitosterol present in the PM represents an interesting issue in further studies dealing with the functional characterization of this enzyme and the regulation of plant sterol metabolism.

Cellular and metabolic engineering approaches aimed at modifying stigmasterol levels in plants represent a very challenging topic in the field of plant biology and biotechnology [11, 77]. In this sense, the progress in this field should certainly benefit from the new advances in the characterization of C22DES at the genetic, cellular and biochemical levels. Although the structural and functional studies carried out in the present work represent a significant contribution towards this end, we believe that future research in this area should pay special attention to better understand the cellular and molecular mechanisms involved in the regulation of C22DES activity considering the different pools of $\beta$-sitosterol present in the plant cell endomembrane system.

\section{Conclusion}

Tomato C22DES is an integral ER-membrane protein having a single transmembrane $\alpha$-helix at the $\mathrm{N}$ terminal end (TMH). Two short sequences able to interact with the ER membrane (MCR1 and MCR2) have also been predicted in the globular domain. TMH is sufficient for the targeting and retention of the enzyme in the ER-membrane. However, the globular domain can also interact and be retained in the ER-membrane in the absence of $\mathrm{TMH}$, which is required for C22DES activity in vivo. The TMH region contains a highly conserved cholesterol recognition/interaction amino-acid consensus (CRAC) motif and is enriched in threonine and serine residues. These features may be relevant for the recognition and uptake of the $\beta$-sitosterol present in the ER membrane to the catalytic site of the enzyme. Overall, the results presented here suggest the existence of a complex pattern of interactions of C22DES with the ERmembrane which are essential for proper enzyme function. The molecular mechanisms underlying the interaction of C22DES with the major cellular pool of $\beta$ sitosterol present in the PM remain unknown and deserve further studies.

\section{Methods \\ Plant material}

Nicotiana benthamiana plants (obtained from the Plant Growth Service of the Center for Research in Agricultural Genomics, Barcelona) were grown under standard greenhouse conditions (14 h light at $26 \pm 1^{\circ} \mathrm{C}$ and $10 \mathrm{~h}$ dark at $21 \pm 1{ }^{\circ} \mathrm{C}$ ) in individual pots of $12 \mathrm{~cm}$ of diameter.

\section{Cloning and plasmid constructions}

All the protein-coding sequences lacking the stop codon used for in-frame fusions of tomato C22DES with the GFP and RFP were amplified by PCR using 35S:C22DES plasmid as a template, which was previously obtained in the laboratory and contained the open reading frame coding for the C22DES (GenBank: NM_001247585). All the PCR reactions were performed using high fidelity 
AccuPrime $^{\text {tw }}$ Taq DNA polymerase (Invitrogen) and specific primer pairs (Additional file 5: Table S2). Amplification products were purified and cloned into pDONR207 donor vector using Gateway technology (Invitrogen) and the resulting pENTRY plasmids transformed into chemically competent Top 10 E. coli cells, which were used for all cloning steps. The cDNA sequences in the resulting pENTRY plasmids were sequenced to confirm the absence of mutations derived from the amplification process. The verified sequences were sub-cloned into the binary vectors pEarleyGate103 [78] and pGWB454 [79] using Gateway technology to respectively generate GFP and RFP fusions at the Cterminus under the control of the CaMV35S promoter. The obtained constructs were confirmed by restriction mapping and DNA sequence analysis.

\section{Agroinfiltration of $\mathrm{N}$. benthamiana leaves}

Subcellular localization assays were performed by expression of C22DES fusions with GFP or RFP proteins in leaves of 3-5-week-old $N$. benthamiana plants grown under standard greenhouse conditions (14 h light at $26 \pm 1{ }^{\circ} \mathrm{C}$ and $10 \mathrm{~h}$ dark at $21 \pm 1^{\circ} \mathrm{C}$ ) in individual pots of $12 \mathrm{~cm}$ diameter. Leaves were infiltrated with suspensions of the different GV3101 A. tumefaciens strains harboring the corresponding recombinant expression plasmids [80, 81], which were prepared as follows. A single positive colony per construct was inoculated into $3 \mathrm{~mL}$ of YEB medium supplemented with the right antibiotics (rifampicin $50 \mu \mathrm{g} / \mathrm{ml}$, gentamycin $25 \mu \mathrm{g} / \mathrm{ml}$ and the plasmid selective antibiotic) and incubated overnight at $28^{\circ} \mathrm{C}$ and at $250 \mathrm{rpm}$ in a continuous rotary shaker. A 1:100 dilution of the overnight culture was inoculated into $25 \mathrm{~mL}$ of YEB medium containing the same antibiotics and incubated under the same conditions. The culture was centrifuged at $5.000 \mathrm{rpm}$ for $15 \mathrm{~min}$ at $4{ }^{\circ} \mathrm{C}$ and the bacterial pellets resuspended in infiltration buffer (10 $\mathrm{mM}$ MES, pH 5.6, $10 \mathrm{mM} \mathrm{MgSO}_{4}$ and $150 \mu \mathrm{M}$ acetosyringone) to reach a final $\mathrm{OD}_{600}$ of 1 . Cultures of the transformed $A$. tumefaciens strains were separately mixed with a culture of $A$. tumefaciens strain expressing HC-Pro [82] in a 1:1 ratio and infiltrated in the abaxial part of $N$. benthamiana leaves using a syringe. For co-expression analysis, the strains harboring the different expression plasmids were mixed in equal proportions and also with HC-Pro (the mix never reaching an $\mathrm{OD}_{600}$ higher than 1). Agroinfiltrated plants were let to grow for 3-4 days under the greenhouse conditions indicated above.

\section{Confocal microscopy}

Agroinfiltrated leaves were cut into small pieces and the abaxial epidermis analyzed with an Olympus FV 1000 confocal laser-scanning microscope using the 60x water immersion NA: 1.20 objective. The emission windows for fluorescence visualization and the conditions used for image acquisition have been described in RamírezEstrada et al. [83]. Fluorescence recovery after photobleaching (FRAP) analysis were also performed as described in Ramírez-Estrada et al. [83]

\section{Sterol analysis}

$N$. benthamiana leaves from three independently agroinfiltrated plants were frozen in liquid nitrogen, ground with a mortar and pestle and lyophilized. Samples (30 $\mathrm{mg}$ ) were mixed with internal standards $[2.5 \mu \mathrm{g}$ of cholestanol, $5 \mu \mathrm{g}$ of palmitoyl-cholestanol, $5 \mu \mathrm{g}$ of cholestanyl- $\beta$-D-glucoside and $5 \mu \mathrm{g}$ of palmitoyl- $\beta$-Dglucosyl-cholestanol in chloroform-methanol (2:1)] and extracted with chloroform-methanol (2:1) as indicated in Ramírez-Estrada et al. [83]. Free sterol, steryl ester, steryl glucoside and acyl steryl glcusoside fractions were separated by TLC and their sterol composition determined by GC-MS as described in Lara et al. (2018) [75]. Total stigmaterol levels were calculated from those present in the four sterol fractions extracted from each sample.

\section{Immunoblot analysis}

Soluble (S) and membrane (M) protein fractions from $N$. benthamiana agroinfiltrated leaves were obtained from approximately $10 \mathrm{~g}$ of tissue samples as previously reported [83]. Protein concentration was determined as described in Bradford et al., 1976 [84]. Equivalent protein amounts of the $\mathrm{T}$ fractions (samples before ultracentrifugation) (around $20 \mu \mathrm{g}$ ), $\mathrm{M}$ fractions (around $5 \mu \mathrm{g}$ ) and $\mathrm{S}$ fractions (around $20 \mu \mathrm{g}$ ) from each leaf sample were fractionated by $10 \%$ polyacrylamide-SDS gel electrophoresis TGX $^{\mathrm{mu}}$ FastCast ${ }^{\mathrm{Tm}}$ Gel (Bio-Rad). After SDS-PAGE, the proteins were transferred to a $0.45 \mu \mathrm{m}$ nitrocellulose membrane (Amersham, GE Healthcare) using the Trans-Blot ${ }^{\oplus}$ Turbo $^{\text {tw }}$ Transfer system (Bio-Rad). Immunoblots using a rabbit anti-GFP antibody (Invitrogen) were performed as described in Ramírez-Estrada et al. [83].

\section{In silico analysis of protein structure}

The 3D structure of the C22DES (NP_001234514.1) was modeled using Phyre2 fold recognition server [85] (http://www.sbg.bio.ic.ac.uk/phyre2). The tertiary structure was predicted using the Lanosterol 14 $\alpha$ Demethylase (Erg11p) of Saccharomyces cerevisiae [Protein Data Bank (PDB) ID: c4lxjA] as a template with $100 \%$ confidence. For membrane-protein interactions, the predicted 3D models were orientated using PPM web server from the Orientations of Proteins in Membranes (OPM) database [31] (https://opm.phar.umich. edu/ppm_server). 


\section{Protein sequence analysis}

$S$. lycopersicum C22DES protein sequence was retrieved from the SolGenomics Network website (http:// solgenomics.net/) and used as query to search for other plant species homologs using the BLAST tool on the Phytozome (https://phytozome.jgi.doe.gov), GenomeNet (https://www.genome.jp/), NCBI (https://www.ncbi.nlm. nih.gov/), PLAZA (https://bioinformatics.psb.ugent.be/ plaza/) and the EnsemblPlants (http://plants.ensembl. org) websites. The accession numbers of the used homologs are listed in Additional file 2: Table S1. Protein alignments were performed using ClustalX v 2.0 [86] with default settings and the GeneDoc software was used for alignment visualizations and manual edition. The criteria for sequence inclusion on the final alignment was choosing one C22DES from each plant family, preferably those in which C22DES was a single-copy gene. For the plant species with more than one C22DES paralog, the selection of just one of them was based on the highest similarity of each paralog with those C22DES from the single-copy species.

For sequence logo generation, WebLogo web server was used [87] (https://weblogo.berkeley.edu/).

\section{Abbreviations}

BLAST: Basic local alignment search tool; C22DES: Sterol C22-desaturase CARC: CRAC specular sequence; CRAC: Cholesterol recognition/interaction amino acid consensus; CYP: Cytochrome P450; DW: Dry weight; ER: Endoplasmic reticulum; FRAP: Fluorescence recovery after photobleaching; GC-MS: Gas chromatography-mass spectrometry; GFP: Green fluorescent protein; HCPRO: HC-Pro silencing supressor; MCR: Membrane contact region; $\mathrm{OD}_{600}$ : Optic density at $600 \mathrm{~nm}$; OPM: Orientation of proteins in membranes; PCR: Polymerase chain reaction; PM: Plasma membrane; RFP: Red fluorescent protein; SD: Standard deviation; SDS: Sodium Dodecyl Sulfate; SDS-PAGE: SDS-Polyacrylamide Gel Electrophoresis; TLC: Thin layer chromatography; TMH: Transmembrane helix motif

\section{Supplementary Information}

The online version contains supplementary material available at https://doi. org/10.1186/s12870-021-02898-7.

\section{Additional file 1: Supplementary Figure S1, Reaction catalyzed by} C22DES

Additional file 2: Supplementary Table S1, List of plant C22 desaturases used for sequence analysis.

Additional file 3: Supplementary Figure S2,Conserved CRAC and CARC motifs present in the globular domain of plant C22DES.

Additional file 4: Supplementary Figure S3, Localization of potentially relevant CRAC and CARC motifs in the predicted 3D structure of tomato C22DES.

Additional file 5: Supplementary Table S2, Primers and vectors used for preparing the constructs of this study.

Additional file 6: Supplementary Figure S4, Full length image of the western blots shown in Fig. 5c.

Additional file 7: Supplementary Figure S5, Full length image of the western blots shown in Fig. $5 d$.

Additional file 8: Supplementary Figure S6, Full length image of the western blot shown in Fig. 6.

\section{Acknowledgements}

LGG received a doctoral fellowship (Ref. BES-2014-070425) from the Ministerio de Economia y Competitividad (Spain). We also thank the staff of the Microscopy and Imaging, Genomics and Plant Growth facilities of the Centre for Research in Agricultural Genomics (CRAG).

\section{Authors' contributions}

$A B$, TA and AF conceived and designed the research; LGG conducted the experimental work with the contribution of MA in the sterol analysis. LGG and $A B$ wrote the manuscript. All authors have read and approved the manuscript.

\section{Funding}

This work was funded by grants AGL2017-88842-R from FEDER/Ministerio de Ciencia, Innovación y Universidades-Agencia Estatal de Investigación (Spain), 2017SGR710 from the Generalitat de Catalunya, and by the CERCA Programme of the Generalitat de Catalunya. We also acknowledge financial support from the Spanish Ministerio de Economía y Competitividad through the "Severo Ochoa Programme for Centres of Excellence in R\&D" 2016-2019 (SEV-2015- 0533). The funders have not been involved in the design of the study, in the collection, analysis, and interpretation of data and in writing the manuscript.

\section{Availability of data and materials}

All data generated or analysed during this study are included in this published article [and its supplementary information files]. The datasets used and/or analysed during the current study are available from the corresponding author on reasonable request.

\section{Declarations}

Ethics approval and consent to participate

Not aplicable.

Consent for publication

Not aplicable.

\section{Competing interests}

The authors declare that they have no competing interests.

\section{Author details}

${ }^{1}$ Center for Research in Agricultural Genomics (CSIC-IRTA-UAB-UB), Bellaterra, Barcelona, Spain. ${ }^{2}$ Department of Biochemistry and Physiology, Faculty of Pharmacy and Food Sciences, University of Barcelona, 08028 Barcelona, Spain. ${ }^{3}$ Department of Biology, Healthcare and the Environment, Faculty of Pharmacy and Food Sciences, University of Barcelona, 08028 Barcelona, Spain. ${ }^{4}$ Department of Biochemistry and Molecular Biomedicine, Faculty of Biology, University of Barcelona, 08028 Barcelona, Spain.

Received: 21 October 2020 Accepted: 21 February 2021

Published online: 17 March 2021

References

1. Demel RA, De Kruyff B. The function of sterols in membranes. Biochem Biophys Acta. 1976;457:109-32.

2. Hartmann-Bouillon M-A, Benveniste P. Sterol biosynthetic capability of purified membrane fractions from maize coleoptiles. Phytochemistry. 1978; 17:1037-42

3. Hartmann M-A. Plant sterols and the membrane environment. Trends Plant Sci. 1998;3(5):170-5

4. Ferrer A, Altabella T, Arró M, Boronat A. Emerging roles for conjugated sterols in plants. Prog Lipid Res. 2017:67:27-37.

5. Boutté Y, Grebe M. Cellular processes relying on sterol function in plants. Curr Opin Plant Biol. 2009:12:705-13.

6. Malinsky J, Opekarová M, Grossmann G, Tanner W. Membrane microdomains, rafts, and detergent-resistant membranes in plants and fungi. Annu Rev Plant Biol. 2013;64:501-29.

7. Valitova JN, Sulkarnayeva AG, Minibayeva FV. Plant sterols: diversity, biosynthesis, and physiological functions. Biochem. 2016;81(8):819-34. 
8. Grosjean K, Mongrand S, Beney L, Simon-Plas F, Gerbeau-Pissot P. Differential effect of plant lipids on membrane organization. J Biol Chem. 2015;290(9):5810-25.

9. Grunwald C. Effects of free sterols, Steryl Ester, and Steryl glycoside on membrane permeability. Plant Physiol. 1971;48(5):653-5.

10. Halling KK, Slotte JP. Membrane properties of plant sterols in phospholipid bilayers as determined by differential scanning calorimetry, resonance energy transfer and detergent-induced solubilization. Biochim Biophys Acta. 2004;1664:161-71.

11. Aboobucker SI, Suza WP. Why do plants convert Sitosterol to Stigmasterol? Front Plant Sci. 2019;10:art. no. 354

12. Griebel T, Zeier J. A role for $\beta$-sitosterol to stigmasterol conversion in plantpathogen interactions. Plant J. 2010;63(2):254-68.

13. Whitaker BD. Changes in lipids of tomato fruit stored at chilling and nonchilling temperatures. Phytochemistry. 1991;30(3):757-61.

14. Morikawa T, Mizutani M, Ohta D. Cytochrome P450 subfamily CYP710A genes encode sterol C-22 desaturase in plants. Biochem Soc Trans. 2006; 34(6):1202-5.

15. Kida Y, Ohgiya S, Mihara K, Sakaguchi M. Membrane topology of NADPHcytochrome P450 reductase on the endoplasmic reticulum. Arch Biochem Biophys. 1998;351(2):175-9.

16. Park JW, Reed JR, Brignac-Huber LM, Backes WL. Cytochrome P450 system proteins reside in different regions of the endoplasmic reticulum. Biochem J. 2014:464(2):241-9.

17. Morikawa T, Mizutani M, Aoki N, Watanabe B, Saga H, Saito S, et al. Cytochrome P450 CYP710A encodes the sterol C-22 Desaturase in Arabidopsis and tomato. Plant Cell. 2006;18:1008-22.

18. Ohta D, Mizutani M. Sterol C22-Desaturase and its biological roles. Isoprenoid synthesis in plants and microorganisms: new concepts and experimental approaches; 2013. p. 381-91.

19. Nelson DR. Cytochrome P450 diversity in the tree of life. Biochim Biophys Acta Proteins Proteomics. 2017;1866(2018):141-54

20. Chen W, Lee M-K, Jefcoate C, Kim S-C, Chen F, Yu J-H. Fungal cytochrome P450 monooxygenases: their distribution, structure, functions, family expansion, and evolutionary origin. Genome Biol Evol. 2014;6(7):1620-34.

21. Arnqvist L, Persson M, Jonsson L, Dutta PC, Sitbon F. Overexpression of CYP710A1 and CYP710A4 in transgenic Arabidopsis plants increases the level of stigmasterol at the expense of sitosterol. Planta. 2008:227:309-17.

22. Morikawa T, Saga H, Hashizume H, Ohta D. CYP710A genes encoding sterol C22-desaturase in Physcomitrella patens as molecular evidence for the evolutionary conservation of a sterol biosynthetic pathway in plants. Planta. 2009;229:1311-22

23. Benveniste P. Biosynthesis and accumulation of sterols. Annu Rev Plant Biol. 2004;55:429-57.

24. Fujioka S, Yokota T. Biosynthesis and metabolism of Brassinosteroids. Annu Rev Plant Biol. 2003;54:137-64.

25. Schaller $\mathrm{H}$. The role of sterols in plant growth and development. Prog Lipid Res. 2003:42:163-75

26. Schuler MA, Duan H, Bilgin M, Ali S. Arabidopsis cytochrome P450s through the looking glass: a window on plant biochemistry. Phytochem Rev. 2006;5: 205-37.

27. Šrejber M, Navrátilová V, Paloncýová M, Bazgier V, Berka K, Anzenbacher P, et al. Membrane-attached mammalian cytochromes P450: an overview of the membrane's effects on structure, drug binding, and interactions with redox partners. J Inorg Biochem. 2018:183:117-36.

28. Forés $\mathrm{O}$, Arró M, Pahissa A, Ferrero S, Germann M, Stukey J, et al. Arabidopsis thaliana expresses two functional isoforms of Arvp, a protein involved in the regulation of cellular lipid homeostasis. Biochim Biophys Acta. 2006;1761:725-35.

29. Monk BC, Tomasiak TM, Keniya MV, Huschmann FU, Tyndall JDA, O'Connel $\mathrm{JD}$, et al. Architecture of a single membrane spanning cytochrome P450 suggests constraints that orient the catalytic domain relative to a bilayer Proc Natl Acad Sci. 2014;111(10):3865-70.

30. Ott RG, Athenstaedt K, Hrastnik C, Leitner E, Bergler H, Daum G. Flux of sterol intermediates in a yeast strain deleted of the lanosterol C-14 demethylase Erg11p. Biochim Biophys Acta. 2005;1735:111-8.

31. Lomize MA, Pogozheva ID, Joo H, Mosberg HI, Lomize AL. OPM database and PPM web server: resources for positioning of proteins in membranes. Nucleic Acids Res. 2012;40:370-6.

32. Gnanasekaran $T$, Vavitsas $K$, Andersen-Ranberg J, Nielsen AZ, Olsen CE Hamberger B, et al. Heterologous expression of the isopimaric acid pathway in Nicotiana benthamiana and the effect of $\mathrm{N}$-terminal modifications of the involved cytochrome P450 enzyme. J Biol Eng. 2015:9(24):1-10.

33. Mustafa G, Nandekar PP, Camp TJ, Bruce NJ, Gregory MC, Sligar SG, et al. Influence of Transmembrane helix mutations on cytochrome P450membrane interactions and function. Biophys J. 2019;116:419-32.

34. Sagara Y, Barnes HJ, Waterman MR. Expression in Escherichia coli of functional cytochrome P450c17 lacking its hydrophobic amino-terminal signal anchor. Arch Biochem Biophys. 1993;304:272-8.

35. Yabusaki Y, Murakami H, Sakaki T, Shibata M, Ohkawa H. Genetically engineered modification of P450 Monooxygenases: functional analysis of the amino-terminal hydrophobic region and hinge region of the P450/ Reductase fused enzyme. DNA. 1988;7(10):701-11.

36. Bunt G, Wouters FS. Visualization of molecular activities inside living cells with fluorescent labels. Int Rev Cytol. 2004;237:205-77.

37. Goehring NW, Chowdhury D, Hyman AA, Grill SW. FRAP analysis of membrane-associated proteins: lateral diffusion and membrane-cytoplasmic exchange. Biophys J. 2010:99:2443-52.

38. Caño-Delgado A, Yin Y, Yu C, Vafeados D, Mora-García S, Cheng J-C, et al. BRL1 and BRL3 are novel brassinosteroid receptors that function in vascular differentiation in Arabidopsis. Development. 2004;131(21):5341-51.

39. Danek Burgess KS, Justice JB. Effects of serine mutations in Transmembrane domain 7 of the human norepinephrine transporter on substrate binding and transport. J Neurochem. 1999:73(2):656-64.

40. Martínez-Garay CA, Juanes MA, Igual JC, Mingarro I, Bañó MC. A transmembrane serine residue in the Rot1 protein is essential for yeast cell viability. Biochem J. 2014;458:239-49.

41. Epand RM, Thomas A, Brasseur R, Epand RF. Cholesterol interaction with proteins that partition into membrane domains : an overview. In: Cholesteron Binding and Cholesterol Transport Proteins; 2010. p. 253-78.

42. Di Scala C, Baier CJ, Evans LS, Williamson PTF, Fantini J, Barrantes FJ. Relevance of CARC and CRAC cholesterol-recognition motifs in the nicotinic acetylcholine receptor and other membrane-bound receptors. In: Current topics in membranes. 1st ed. Cambridge: Elsevier Inc; 2017;80:3-23.

43. Jamin N, Neumann J-M, Ostuni MA, Vu TKN, Yao ZX, Murail S, et al. Characterization of the cholesterol recognition amino acid consensus sequence of the peripheraltype benzodiazepine receptor. Mol Endocrinol. 2005:19(3):588-94.

44. Singh AK, McMillan J, Bukiya AN, Burton B, Parrill AL, Dopico AM. Multiple cholesterol recognition/interaction amino acid consensus (CRAC) motifs in cytosolic C tail of Slo1 subunit determine cholesterol sensitivity of Ca2+and voltage-gated K+ (BK) channels. J Biol Chem. 2012;287(24):20509-21.

45. Scott EE, Wolf CR, Otyepka M, Humphreys SC, Reed JR, Henderson CJ, et al. The role of protein-protein and protein-membrane interactions on P450 function. Drug Metab Dispos. 2016:44:576-90.

46. Locuson CW, Wienkers LC, Jones JP, Tracy TS. CYP2C9 protein interactions with cytochrome b5: effects on the coupling of catalysis. Drug Metab Dispos. 2007;35(7):1174-81.

47. Subramanian M, Low M, Locuson CW, Tracy TS. CYP2D6-CYP2C9 proteinprotein interactions and isoform-selective effects on substrate binding and catalysis. Drug Metab Dispos. 2009:37(8):1682-9.

48. Subramanian M, Tam H, Zheng H, Tracy TS. CYP2C9-CYP3A4 protein-protein interactions: role of the hydrophobic N terminus. Drug Metab Dispos. 2010; 38(6):1003-9.

49. Im S-C, Waskell L. The interaction of microsomal cytochrome P450 2 B4 with its redox partners, cytochrome P450 Reductase and cytochrome b5. Arch Biochem Biophys. 2011;507(1):144-53.

50. Nelson CH, Peng C-C, Lutz JD, Yeung CK, Zelter A. Direct protein-protein interactions and substrate channelling between cellular retinoic acid binding proteins and CYP26B1. FEBS Lett. 2016;590(16):2527-35.

51. Scheller U, Kraft R, Schröder K-L, Schunck W-H. Generation of the soluble and functional cytosolic domain of microsomal cytochrome P450 52A3. J Biol Chem. 1994;269(17):12779-83.

52. Clark BJ, Waterman MR. The hydrophobic amino-terminal sequence of bovine 17a-hydroxylase is required for the expression of a functional hemoprotein in COS 1 cells. J Biol Chem. 1991:266(9):5898-904.

53. Berka K, Paloncýová M, Anzenbacher P, Otyepka M. Behavior of human cytochromes P450 on lipid membranes. J Phys Chem B. 2013;117:11556-64.

54. Yu X, Cojocaru V, Mustafa G, Salo-Ahen OMH, Lepesheva Gl, Wade RC. Dynamics of CYP51: implications for function and inhibitor design. J Mol Recognit. 2015;28(2):59-73

55. Fantini J, Di Scala C, Baier CJ, Barrantes FJ. Molecular mechanisms of protein-cholesterol interactions in plasma membranes : functional 
distinction between topological (tilted) and consensus (CARC/CRAC) domains. Chem Phys Lipids. 2016;199:52-60.

56. Li H, Yao Z-X, Degenhardt B, Teper G, Papadopoulos V. Cholesterol binding at the cholesterol recognition/interaction amino acid consensus (CRAC) of the peripheral-type benzodiazepine receptor and inhibition of steroidogenesis by an HIV TAT-CRAC peptide. Proc Natl Acad Sci U S A. 2001;98(3):1267-72.

57. Jafurulla M, Tiwari S, Chattopadhyay A. Identification of cholesterol recognition amino acid consensus (CRAC) motif in G-protein coupled receptors. Biochem Biophys Res Commun. 2011:404:569-73.

58. Di Scala C, Chahinian H, Yahi N, Garmy N, Fantini J. Interaction of Alzheimer's $\beta$-amyloid peptides with cholesterol: mechanistic insights into amyloid pore formation. Biochemistry. 2014;53(28):4489-502.

59. Tan S, Zhang P, Xiao W, Feng B, Chen L-Y, Li S, et al. TMD1 domain and CRAC motif determine the association and disassociation of MXIRT1 with detergent-resistant membranes. Traffic. 2017;19:122-37.

60. Desai AJ, Dong M, Miller LJ. Beneficial effects of $\beta$-sitosterol on type 1 cholecystokinin receptor dysfunction induced by elevated membrane cholesterol. Clin Nutr. 2016:35(6):1374-9.

61. Rosenhouse-Dantsker A. Insights into the molecular requirements for cholesterol binding to ion channels. Curr Top Membr. 1st ed. Cambridge: Elsevier Inc; 2017;80:187-208.

62. Klahre U, Noguchi T, Fujioka S, Takatsuto S, Yokota T, Nomura T, et al. The Arabidopsis DIMINUTO/DWARF1 gene encodes a protein involved in steroid synthesis. Plant Cell. 1998;10:1677-90.

63. Souter M, Topping J, Pullen M, Friml J, Palme K, Hackett R, et al. Hydra mutants of Arabidopsis are defective in sterol profiles and Auxin and ethylene signaling. Plant Cell. 2002;14:1017-31.

64. Carland F, Fujioka S, Nelson T. The sterol Methyltransferases SMT1, SMT2, and SMT3 influence Arabidopsis development through Nonbrassinosteroid products. Plant Physiol. 2010;153:741-56.

65. Jensen K, Møller BL. Plant NADPH-cytochrome P450 oxidoreductases. Phytochemistry. 2010;71:132-41.

66. Wang P, Hawes C, Hussey PJ. Plant endoplasmic reticulum-plasma membrane contact sites. Trends Plant Sci. 2017;22(4):289-97.

67. Manford AG, Stefan CJ, Yuan HL, MacGurn JA, Emr SD. ER-to-plasma membrane tethering proteins regulate cell signaling and ER morphology. Dev Cell. 2012;23:1129-40.

68. Zang J, Zhang T, Hussey PJ, Wang P. Light microscopy of the endoplasmic reticulum-membrane contact sites in plants. J Microsc. 2020;0(0):134-9.

69. Stefan CJ, Manford AG, Baird D, Yamada-Hanff J, Mao Y, Emr SD. Osh proteins regulate Phosphoinositide metabolism at ER-plasma membrane contact sites. Cell [Internet]. 2011;144:389-401. https://doi.org/10.1016/j.cell.2 010.12 .034 .

70. Haj FG, Sabet O, Kinkhabwala A, Wimmer-Kleikamp S, Roukos V, Han H-M, et al. Regulation of signaling at regions of cell-cell contact by endoplasmic reticulum-bound protein-tyrosine phosphatase 1B. PLoS One. 2012;7(5):art. no. e36633.

71. Mehrshahi P, Stefano G, Andaloro JM, Brandizzi F, Froehlich JE, DellaPenna D. Transorganellar complementation redefines the biochemical continuity of endoplasmic reticulum and chloroplasts. Proc Natl Acad Sci U S A. 2013; 110(29):12126-31.

72. Tavassoli S, Chao JT, Young BP, Cox RC, Prinz WA, De Kroon AIPM, et al. Plasma membrane - endoplasmic reticulum contact sites regulate phosphatidylcholine synthesis. EMBO Rep. 2013:14(5):434-40.

73. Quon E, Sere YY, Chauhan N, Johansen J, Sullivan DP, Dittman JS, et al. Endoplasmic reticulum-plasma membrane contact sites integrate sterol and phospholipid regulation. PLoS Biol. 2018;16:1-41.

74. Prinz WA, Toulmay A, Balla T. The functional universe of membrane contact sites. Nat Rev Mol Cell Biol. 2020;21(1):7-24.

75. Lara JA, Burciaga-Monge A, Chávez A, Revés M, Lavilla R, Arró M, et al. Identification and characterization of sterol Acyltransferases responsible for Steryl Ester biosynthesis in tomato. Front Plant Sci. 2018;9(May):1-18.

76. Stolowich NJ, Petrescu AD, Huang H, Martin GG, Scott Al, Schroeder F. Sterol carrier protein-2 : structure reveals function. Cell Mol Life Sci. 2002;59: 193-212.

77. Sharma A, Rana S, Rather GA, Misra P, Dhar MK, Lattoo SK. Characterization and overexpression of sterol $\Delta 22$-desaturase, a key enzyme modulates the biosyntheses of stigmasterol and withanolides in Withania somnifera (L.) Dunal. Plant Sci. 2020;301:1-11. https://doi.org/10.1016/j. plantsci.2020.110642.
78. Earley KW, Haag JR, Pontes O, Opper K, Juehne T, Song K, et al. Gatewaycompatible vectors for plant functional genomics and proteomics. Plant J. 2006;45(4):616-29

79. Nakagawa T, Suzuki T, Murata S, Nakamura S, Hino T, Maeo K, et al. Improved gateway binary vectors: high-performance vectors for creation of fusion constructs in transgenic analysis of plants. Biosci Biotechnol Biochem. 2007;71(8):2095-100

80. Sparkes IA, Runions J, Kearns A, Hawes C. Rapid, transient expression of fluorescent fusion proteins in tobacco plants and generation of stably transformed plants. Nat Protoc. 2006;1(4):2019-25.

81. Wydro M, Kozubek E, Lehmann P. Optimization of transient agrobacteriummediated gene expression system in leaves of Nicotiana benthamiana. Acta Biochim Pol. 2006;53(2):289-98.

82. Goytia E, Fernández-Calvino L, Martínez-García B, López-Abella D, LópezMoya JJ. Production of plum pox virus HC-pro functionally active for aphid transmission in a transient-expression system. J Gen Virol. 2006;87:3413-23.

83. Ramírez-Estrada K, Castillo N, Lara JA, Arró M, Boronat A, Ferrer A, et al. Tomato UDP-glucose sterol Glycosyltransferases : a family of developmental and stress regulated genes that encode cytosolic and membrane-associated forms of the enzyme. Front Plant Sci. 2017:8(June):1-21.

84. Bradford MM. A rapid and sensitive method for the quantitation of microgram quantities of protein utilizing the principle of protein-dye binding. Anal Biochem. 1976;72:248-54

85. Kelley LA, Mezulis S, Yates CM, Wass MN, Sternberg MJE. The Phyre2 web portal for protein modelling, prediction, and analysis. Nat Protoc. 2015;10(6): 845-58.

86. Larkin MA, Blackshields G, Brown NP, Chenna R, McGettigan PA, McWilliam $H$, et al. Clustal W and Clustal X version 2.0. Bioinformatics. 2007;23(21): 2947-8.

87. Crooks GE, Hon G, Chandonia J-M, Brenner SE. WebLogo: a sequence logo generator. Genome Res. 2004;14:1188-90.

\section{Publisher's Note}

Springer Nature remains neutral with regard to jurisdictional claims in published maps and institutional affiliations.

Ready to submit your research? Choose BMC and benefit from:

- fast, convenient online submission

- thorough peer review by experienced researchers in your field

- rapid publication on acceptance

- support for research data, including large and complex data types

- gold Open Access which fosters wider collaboration and increased citations

- maximum visibility for your research: over $100 \mathrm{M}$ website views per year

At $\mathrm{BMC}$, research is always in progress.

Learn more biomedcentral.com/submissions 